\title{
Conflitos bioéticos sobre distanciamento social em tempos de pandemia
}

Carlise Rigon Dalla Nora

Universidade Federal do Rio Grande do Sul, Porto Alegre/RS, Brasil.

\section{Resumo}

Este artigo objetiva refletir sobre a medida de distanciamento social no cenário de pandemia de covid-19 sob o enfoque da bioética em saúde coletiva. Trata-se de estudo reflexivo que discute o conflito entre o respeito às medidas de distanciamento social e a liberdade individual, utilizando reportagens disponíveis em jornais on-line para exemplificar os argumentos envolvidos e contribuir com a reflexão. A temática foi analisada a partir do principialismo e da bioética social, buscando elementos que possam guiar o processo decisório. Conclui-se que a bioética é instrumental para a reflexão de usuários e profissionais da saúde, e ressalta-se a responsabilidade do Estado em prevenir doenças e garantir a saúde. Propõem-se que o risco para a saúde pública deve prevalecer sobre o individualismo. Palavras-chave: Ética. Bioética. Infecções por coronavírus. Saúde pública.

\section{Resumen}

\section{Conflictos bioéticos sobre el distanciamiento social en tiempos de pandemia}

Este artículo pretende reflexionar sobre las medidas de distanciamiento social en el escenario pandémico de la covid-19 bajo el enfoque de la bioética en salud pública. Se trata de un estudio reflexivo que discute el conflicto entre el respeto a las medidas de distanciamiento social y la libertad individual, utilizando informes disponibles en periódicos en línea para ejemplificar los argumentos involucrados y contribuir a la reflexión. El tema fue analizado desde el principialismo y la bioética social, buscando elementos que puedan guiar el proceso de toma de decisiones. Se concluye que la bioética aparece como un instrumento para la reflexión de usuarios y profesionales de la salud y se enfatiza la responsabilidad del Estado en la prevención de enfermedades y garantía de la salud. Se propone la prevalencia del riesgo de salud pública sobre el individualismo.

Palabras clave: Ética. Bioética. Infecciones por coronavirus. Salud pública.

\section{Abstract}

\section{Bioethical conflicts over social distance in times of pandemic}

This article reflects on social distancing measures in the covid-19 pandemic scenario, based on a bioethical perspective in public health. The research also discusses conflicts between respecting social distancing measures and individual freedoms, using reports available from online newspapers to exemplify relevant arguments and contribute to the overall debate. The topic was analyzed on the basis of principlism and social bioethics, in an attempt to uncover elements that may guide the decisionmaking process. The article concludes that bioethics is an instrumental tool for healthcare users and professionals, emphasizing the State's responsibility to prevent diseases and ensure health. Finally, we argue that the need to deal with immediate public-health risks should prevail over individualism. Keywords: Ethics. Bioethics. Coronavirus infections. Public health. 
A síndrome respiratória aguda grave causada pelo Sars-CoV-2 é denominada "doença do coronavírus 2019" (covid-19) e foi relatada pela primeira vez na cidade de Wuhan, Província de Hubei, China, em dezembro de $2019^{1,2}$. A doença se espaIhou por todo o mundo, chegando finalmente à América Latina ${ }^{3}$, e levou governos a adotar diversas medidas em resposta à pandemia resultante. Entre elas se destacam intervenções físicas não farmacológicas, como higienização das mãos, etiqueta respiratória e distanciamento social, como as mais eficientes até o momento ${ }^{4}$.

As medidas de distanciamento envolvem o fechamento prolongado de escolas, templos religiosos e atrações turísticas, afastamento do local de trabalho e suspensão de competições esportivas, entre outras ações do tipo, com as quais o Estado visa promover distanciamento físico entre as pessoas, de forma a evitar aglomerações. Estudo realizado em Wuhan concluiu que intervenções não farmacêuticas baseadas no distanciamento físico sustentado têm forte potencial para reduzir a magnitude do pico epidêmico da covid-19 e o número de casos gerais ${ }^{5}$.

Evidências apontam que o vírus causador da covid-19 pode se espalhar por contato direto, indireto (mediante superfícies ou objetos contaminados) ou próximo (à distância de um metro) com pessoas infectadas, quando secreções como a saliva ou gotículas respiratórias infecciosas - expelidas por tosse, espirro, fala ou canto - entram em contato com a boca, o nariz ou os olhos da pessoa saudável $^{6}$. Embora não tenha sido possível determinar o impacto de cada medida, estudo observou que a combinação de intervenções (testes de diagnóstico, manejo clínico, rápido isolamento de casos suspeitos, confirmados e contatos, e, mais notavelmente, restrições à mobilidade) foi claramente bem-sucedida em reduzir a transmissão local da covid-197.

A sobrecarga nos recursos humanos e materiais disponíveis é uma das condições para estabelecer crise de saúde pública ${ }^{8}$. Medidas de controle de surtos destinadas a mitigar a transmissão de doenças têm potencial para retardar o pico e reduzir a extensão final da pandemia ${ }^{5}$. Por outro lado, se essas restrições forem alteradas prematura e repentinamente, podem ocorrer novos picos de casos de covid-19 ${ }^{8}$.

No âmbito das práticas de saúde, a bioética tem sido importante recurso para o processo decisório e para a mediação de problemas éticos ${ }^{9}$. No contexto atual, um desses dilemas tem sido o conflito entre manter a recomendação do distanciamento social para controlar a pandemia de covid-19 (consciência do cuidado coletivo) e a liberdade individual (consciência do cuidado pessoal). Ou seja, a autonomia para organizar a vida individual e social segundo as próprias opções e convicções fica limitada, tendo em vista a recomendação de distanciamento social.

Neste estudo, a bioética é abordada não como modelo de ética filosófica, mas como ética aplicada que interpreta, com base no agir humano, ações concretas relativas à vida, à saúde e ao ambiente ${ }^{10}$. Assim, acredita-se ser necessário discutir a interface entre bioética e saúde coletiva, as quais abrangem determinantes sociais, subjetivos, contextuais e ambientais da saúde?

Essa aproximação da bioética com a saúde coletiva pode instruir as decisões no contexto pandêmico ao fomentar reflexões sobre como garantir valores como responsabilidade, transparência e confiança, os quais precisam ser cuidadosamente pensados pelos governantes. Nesse sentido, este estudo objetiva refletir a medida de distanciamento social no cenário de covid-19 sob o enfoque da bioética em saúde coletiva.

\section{Método}

Trata-se de estudo reflexivo que visa responder à seguinte questão de pesquisa: é razoável impor o distanciamento social em detrimento da liberdade individual para controlar a pandemia de covid-19? Este texto foi elaborado a partir de reflexões pessoais e de diálogos com autores da área da saúde coletiva e bioética, lançando mão de reportagens disponíveis em jornais on-line para exemplificar e contribuir com a reflexão.

As reportagens foram procuradas no motor de buscas Google em setembro de 2020 a partir da seguinte frase: "morador que testou positivo para covid-19 é preso ao sair de casa". Dentre inúmeras reportagens que circularam na mídia sobre o tema, selecionaram-se três ${ }^{11-13}$, consideradas representativas do que se deseja mostrar: o cerceamento da liberdade de pessoas com diagnóstico positivo de covid-19. As reportagens selecionadas foram analisadas e ponderadas com base nos princípios 
bioéticos propostos por Beauchamp e Childress ${ }^{14} \mathrm{e}$ na bioética social ${ }^{15}$.

\section{Conflitos bioéticos: distanciamento social e liberdades individuais}

Mesmo após séculos de uso, medidas de distanciamento social persistem como principal ferramenta pública de intervenção em saúde no século XXI devido à sua capacidade de restringir a propagação de doenças. Para maximizar os benefícios desse comportamento, essas medidas devem ser planejadas e instituídas já no início da epidemia ${ }^{16}$. Em situações como essa, a sociedade passa a se comportar em modo de excepcionalidade, e medidas políticas que jamais seriam aceitas fora desse contexto passam a ser consideradas ${ }^{15}$.

Como a covid-19 é transmitida por gotículas respiratórias e exige certa proximidade entre pessoas, as medidas de distanciamento social visam a diminuir a interação entre indivíduos a fim de desacelerar a disseminação do vírus ${ }^{17}$. Essas medidas são costumeiramente adotadas quando já existe transmissão comunitária, ou seja, quando a ligação entre os casos já não pode ser rastreada e o isolamento das pessoas expostas é insuficiente para frear a transmissão ${ }^{18}$. Essas medidas permitem aos gestores estruturar e ampliar a capacidade de resposta da rede de atenção à saúde.

Estudo verificou que a adoção precoce de medidas de distanciamento social e suspensão de aulas influenciou o curso da transmissibilidade, resultando em menor número de óbitos por covid-19 em determinados países ${ }^{19}$. Em Singapura, Coreia do Sul e Japão, a implementação imediata do distanciamento social, o gerenciamento rigoroso dos casos e o diagnóstico em massa colaboraram para conter a disseminação do vírus ${ }^{19}$.

Até o momento - em março de 2021, quando da publicação deste artigo -, o coronavírus já matou mais de dois milhões de pessoas no mundo ${ }^{6} \mathrm{e}$, de acordo com dados do Ministério da Saúde ${ }^{20}$, já são mais de 260 mil mortes no Brasil. Nesse sentido, medidas não farmacológicas de saúde pública precisam ser implementadas para conter a pandemia.

No Brasil, o Ministério da Saúde ${ }^{18}$ apresentou algumas estratégias como medidas de distanciamento social. A primeira delas foi o bloqueio total (lockdown), o mais alto nível de segurança, que busca interromper qualquer atividade por curto período de tempo. Durante esse bloqueio, todas as entradas do perímetro isolado são fechadas por trabalhadores de segurança, e ninguém tem permissão para entrar ou sair ${ }^{18}$.

O distanciamento social ampliado, por sua vez, exige que todos os setores da sociedade permaneçam em casa durante a vigência da medida ${ }^{18}$. A estratégia visa restringir o contato entre pessoas, mantendo apenas serviços essenciais e com maior rigor na higiene, evitando-se aglomerações. O distanciamento ampliado é fundamental para evitar a aceleração descontrolada do contágio, o que poderia provocar o colapso do sistema de saúde, com maior demanda por leitos e respiradores em âmbito hospitalar do que o disponível ${ }^{18}$.

Já no distanciamento social seletivo, apenas alguns grupos são isolados - pessoas sintomáticas e seus contatos domiciliares, assim como os grupos com maior risco de desenvolver a doença ou aqueles que podem apresentar quadro mais grave, como idosos e pessoas com doenças crônicas ${ }^{18}$. Nessa estratégia, pessoas com menos de 60 anos de idade podem circular livremente, mantendo o distanciamento social e cuidados higiênicos, se estiverem assintomáticas. Essa medida pode ser adotada em modelo de transição, a fim de se evitar a passagem de situação mais restritiva para mais livre em curto período ${ }^{18}$.

Isto posto, quando pensada para a saúde coletiva, a bioética pode auxiliar na reflexão e no enfrentamento da pandemia de covid-19, permitindo o desenvolvimento racional de estratégias baseado nos direitos humanos, na responsabilidade coletiva, no princípio da precaução e na solidariedade intergeracional, visando evitar danos à saúde humana ${ }^{21}$. Na pandemia de covid-19, qualquer decisão ética em saúde precisa atender aos pressupostos dos direitos humanos consagrados em acordos internacionais, não agredir o ordenamento jurídico dos Estados e ser deliberada à luz da bioética ${ }^{15}$.

No Brasil, mensagens de alerta sobre a importância do distanciamento social foram veiculadas logo após os primeiros casos de covid-19. Contudo, reportagens que circularam nos jornais demonstraram conflitos entre liberdade, direitos individuais e necessidade de intervenção do Estado: "Morador de rua com coronavírus foge de isolamento em albergue e é preso em MT" 11; "Jovem com covid-19 
sai de quarentena, vai a festa e futebol e é preso no RS" 12; "MP vai investigar conduta de homem com covid-19 que desrespeitou isolamento e foi a restaurante em SC" ${ }^{13}$.

Esse tipo de reportagem circula na internet desde o final de março de 2020 - quando a pandemia começou a se disseminar em todo o território brasileiro - e apresenta casos de pessoas que, por não cumprirem o isolamento recomendado pelos profissionais da saúde, acabaram sofrendo sanções do Estado. Se é razoável impor o distanciamento social em detrimento da liberdade individual para controlar a pandemia de covid-19 é questão que não se esgota no campo da bioética, envolvendo também a saúde coletiva. Com isso, este artigo aponta alguns caminhos para a tomada de decisão, mantendo-se aberto à necessidade de aprofundamento futuro.

Conceitos como "liberdades individuais", "autonomia", "autodeterminação" e "interesse coletivo" são importantes para prosseguir com as reflexões. Entende-se que as liberdades individuais são o princípio fundamental de humanos adultos e, segundo argumenta Mill ${ }^{22}$, o poder somente pode ser exercido por direito sobre qualquer membro de comunidade civilizada contra a sua vontade para evitar danos a outros. Ou seja, cada indivíduo deve ser livre para decidir o próprio destino, desde que não prejudique terceiros.

O termo "autonomia" refere-se a autogoverno, e para que o indivíduo seja autônomo, isto é, apto para fazer suas próprias escolhas, é necessário que seja capaz e livre para agir intencionalmente ${ }^{23}$. A autonomia pessoal consiste na autolegislação, sem interferências ou controle de outros. A pessoa que exerce autonomia é capaz de tomar decisões quanto a assuntos que afetam sua vida, saúde, integridade físico-psíquica e relações sociais, de acordo com suas expectativas, necessidades, prioridades, crenças e valores ${ }^{24}$.

Já a autodeterminação representa conjunto de comportamentos e habilidades que dotam a pessoa da capacidade de agir intencionalmente em relação a seu futuro. Para isso, o indivíduo deve contar com quatro premissas básicas: ser autônomo, autorregulado, ter expressão de empoderamento psicológico e resultar em autorrealização ${ }^{25}$. Quando se pensa em distanciamento social, este também tem implicações éticas, considerando o conflito de interesses entre o direito individual de autodeterminação e a necessidade de cooperação que sustenta a lógica de diminuição da curva de contágio pela covid-19.

O princípio de interesse coletivo é difícil de definir e está expresso na Constituição brasileira ${ }^{26}$. Tal conceito repousa na persecução do bem comum e no respeito à dignidade da pessoa humana, sendo fundamento, critério e limite de todo agir da administração pública. Ou seja, trata-se de noção abstrata, porém com assento constitucional, que remete ao ideal de obtenção do "bem comum" ${ }^{27}$. Quando esse bem comum está em jogo, o interesse coletivo passa a ter prioridade sobre o interesse individual ${ }^{28}$, como em situações de pandemia, em que a rígida restrição das liberdades individuais pode ser legítima, estando previstas em lei medidas que objetivam a proteção da coletividade no contexto atual, tais ações estão ordenadas pela Lei 13.979/2020 ${ }^{29}$. Entende-se, dessa forma, que a autonomia não deve ser respeitada em concepção excessivamente individualista, que nega a natureza social das pessoas, desconsiderando a influência do coletivo nas escolhas e atitudes individuais ${ }^{24}$.

As chamadas "ações coletivas em saúde pública" visam melhorar a saúde da população ${ }^{30}$, objetivando efeito geral, global e impessoal, e, na maioria das vezes, possuem características preventivas, que procuram impedir agravos na saúde ${ }^{31}$. A bioética na prática diária dos profissionais da saúde envolve reflexões sobre a tomada de decisão sem coação de valores, com base no exercício da liberdade, sem constrangimentos ou preconceitos e com respeito a divergências ${ }^{32}$. A bioética fundamenta a relação dos profissionais da saúde com a comunidade, agindo não para causar danos ou prejuízos, mas para garantir a autonomia e o bem-estar de cada pessoa.

Merece destaque o documento publicado em 2002 pela Sociedade de Liderança em Saúde Pública ${ }^{33}$, que enfatizou que a prática em saúde coletiva será ética quando respeitar direitos dos indivíduos e da comunidade. Nesse sentido, crê-se que o distanciamento social para proteger a saúde da população entra em conflito com direitos individuais de liberdade e autodeterminação ${ }^{34}$.

Acredita-se não ser possível pensar práticas de cuidado em saúde desassociadas da bioética, pois esta auxilia a tomar decisões em situação pandêmica, na qual se confrontam princípios, valores e direitos das pessoas e da sociedade em geral ${ }^{35}$. Assim, a ética aplicada em saúde 
coletiva visa enfrentar desafios sociais no processo saúde-doença, e por isso pode-se falar em problemas éticos no campo da saúde coletiva. Esses dilemas são situações que inquietam e perturbam a consciência dos profissionais da saúde. São desafios, fontes de conflito de valores e deveres, com várias soluções possíveis, o que requer ponderação e deliberação para se encontrar o melhor caminho ${ }^{36}$.

Os problemas éticos na atenção primária à saúde estão presentes em circunstâncias comuns da prática diária, sendo por vezes difícil identificá-los, pois são mais sutis que questões tipicamente envolvidas em situações extremas ${ }^{37}$. Isso exacerba a complexidade dos aspectos éticos na saúde coletiva, ampliando a gama de valores associados. A tomada de decisão ética está relacionada à competência ética e à autonomia dos profissionais da saúde ${ }^{36}$.

Nesse contexto, ao pensar o cenário de covid-19 no âmbito da saúde coletiva, encontram-se valores em conflito: por um lado, o respeito às medidas de distanciamento social a fim de se atender à responsabilidade coletiva; por outro, o respeito às liberdades individuais do sujeito e à sua livre circulação. Compreender os valores em conflito permite refletir que não existe solução "pronta"; ao contrário, é preciso reavaliar e propor estratégias continuamente e de modo criativo para descobrir alternativas de longo alcance. Da mesma forma, é importante considerar que cada valor em conflito tem relevância e, por isso, a decisão ética é desafiadora. Fala-se, portanto, em problema ético quando um ou mais valores considerados importantes estão em tensão e não há resposta clara sobre qual deve ser privilegiado, sendo necessário reforçar a reflexão sobre o tema.

Nesse sentido, a bioética surge para abordar conflitos morais e éticos surgidos no âmbito das ações em saúde e das ciências biomédicas ${ }^{28}$. Assim, esse campo do conhecimento pode ser considerado ferramenta legítima e eficiente para a análise crítica das medidas de distanciamento social e como auxílio para tomadas de decisão eticamente justificadas ${ }^{28}$. Com isso, neste estudo são apresentadas brevemente algumas questões bioéticas que motivaram a reflexão com base no principialismo e na bioética social.

A bioética principialista abrange quatro preceitos amplamente divulgados - autonomia, beneficência, não maleficência e justiça ${ }^{14}$-, pensados para enfrentar problemas da relação entre indivíduos e que não podem ser aplicados de maneira cega e fechada no âmbito público da saúde, porque perdem a especificidade coletiva e social ${ }^{38}$. A observância desses princípios é essencial em pandemias, mas os conceitos adquirem novos aspectos nesse contexto ${ }^{39}$. Sua aplicação pode ser pensada como obrigação prima facie $^{26}$, ou seja, que deve ser cumprida a menos que conflite com outra obrigação de igual ou maior força ${ }^{24}$.

Esses princípios podem entrar em conflito principalmente no contexto de ações coletivas, como é o caso das medidas de distanciamento social. Por exemplo, se o indivíduo com covid-19 escolhe autonomamente sair para a rua - ameaçando a saúde pública, causando danos a terceiros e demandando indevidamente o uso de recursos escassos, como leitos de unidade de terapia intensiva -, sua autonomia está em conflito com o interesse da proteção coletiva, pois neste caso a manutenção da autonomia individual implica em risco real para toda a comunidade ${ }^{28}$. Nesse enfoque, nas situações em que o bem comum está em jogo, o interesse coletivo passa a ter prioridade sobre o interesse individual, como é atualmente o exemplo da pandemia, em que a rígida restrição das liberdades individuais pode ser legítima ${ }^{40} \mathrm{em}$ função do benefício ao próprio indivíduo ou à coletividade ${ }^{28}$.

Ademais, atender somente a liberdade individual coloca em xeque o princípio da não maleficência, que compreende a obrigação de minimizar os riscos para a população em geral ${ }^{39}$. Causar mal ou danos a outro é moralmente reprovável, estendendo-se a aplicação desse princípio a todas as pessoas ${ }^{41}$. Facultar ao indivíduo aderir ou não a medidas de distanciamento social opõe-se totalmente a esse preceito ao pôr em risco a coletividade. Nesse caso, em que há evidente tensão entre interesse individual e bem coletivo, a liberdade individual (autonomia) perde valor em relação aos interesses da coletividade (bem comum) ${ }^{42}$. Nesse sentido, não se pode ter receio de aplicar medidas de emergência em situações de pandemia, nem de recusá-las caso o contexto se altere.

Da mesma forma, o princípio da beneficência leva ao dever de tratar doentes e ajudar a sociedade. Esse preceito estabelece a obrigação moral de ajudar outras pessoas, promovendo seus interesses legítimos e importantes, ainda que seja condicional ou dependente da situação apresentada ${ }^{41}$. Beauchamp e Childress ${ }^{14}$ consideram que 
o princípio da beneficência exige mais que a não maleficência, pois os agentes precisam tomar atitudes positivas para ajudar os outros, não meramente se abster de praticar atos nocivos.

O princípio da justiça também limita a autonomia no caso analisado ao obrigar as pessoas ao distanciamento social, impedindo o direito consagrado de ir e vir ${ }^{15}$. Esse princípio trata da distribuição justa de benefícios sociais, e no contexto de pandemia os recursos em escala global são limitados $^{39}$. É comum acrescentar a ele o conceito de equidade - dar a cada pessoa o que lhe é devido, segundo suas necessidades ${ }^{43}$. De acordo com Schramm ${ }^{44}$, ajudar aqueles que não dispõem dos meios para sobreviver dignamente é primordial para respeitar concretamente o princípio da justiça, já que aplicar o valor da equidade como meio de atingir a igualdade é condição sine qua non da sua efetivação. O princípio da justiça supõe intervenção positiva do Estado na área da saúde.

Nesse contexto, a tomada de decisão precisa superar a perspectiva da ética individual, pois a vontade pessoal pode ter consequências ruins para a coletividade. Esse posicionamento é difícil, já que envolve privação significativa da liberdade individual em nome da saúde coletiva. O distanciamento social expõe a tensão entre os interesses da sociedade em proteger a saúde de seus cidadãos e as liberdades civis dos indivíduos, como privacidade e livre circulação ${ }^{16}$, pondo em xeque sua autonomia.

Embora as liberdades civis sejam protegidas pela Declaração Universal dos Direitos Humanos ${ }^{45}$, as ameaças em larga escala à saúde pública podem exigir medidas extraordinárias por parte do Estado. Para que essas ações sejam prudentes, os benefícios para o coletivo devem superar os potenciais encargos ou malefícios aos indivíduos ${ }^{14}$. Desse modo, o distanciamento social deve ser voluntário sempre que possível e, quando impossível, deve ser aplicado pelos meios menos invasivos disponíveis.

Em outra vertente, Schramm e Kottow ${ }^{46}$ argumentam que os problemas éticos inerentes às práticas de saúde coletiva não podem ser satisfatoriamente equacionados com o modelo principialista, mais adequado para discutir conflitos da bioética clínica. A bioética social, por sua vez, produzida na América Latina a partir dos anos 1990, considera temas relacionados à vulnerabilidade socioeconômica, como falta de acesso à saúde, exclusão social, fome e violência ${ }^{15}$.
Entende-se, com isso, que a bioética social também deve ser considerada ferramenta legítima e eficiente para a análise crítica das medidas de distanciamento social. A principal contribuição dessa vertente no contexto da pandemia é o favorecimento de grupos socialmente fragilizados, fomentando políticas públicas prioritárias para resguardar os mais vulneráveis ${ }^{15}$. Compreende-se que a bioética social estimula ações eticamente justificadas no âmbito da saúde coletiva.

Os principais conflitos evidenciados nas reportagens ${ }^{11-13}$ também podem ser ponderados a partir da bioética social, pois há confronto entre interesses coletivos e individuais. O Brasil apresenta déficit importante em termos de habitação, com milhões de pessoas sem moradia e/ou vivendo em condições precárias, sem acesso a água potável e saneamento básico, fatores que favorecem a propagação de diversas doenças, entre elas a covid-19 ${ }^{47}$.

Medidas adotadas pelo Estado precisam considerar as diferentes vulnerabilidades do território. Assim, as diferenças e desigualdades entre os diversos grupos populacionais precisam ser ponderadas, tanto para compreender o difícil contexto pelo qual todos passam quanto para pensar coletivamente formas de enfrentar a epidemia ${ }^{47}$. Organizações do campo da saúde que participam do plano Frente pela Vida ${ }^{47}$ destacam ações que podem ser tomadas pelo governo, como acomodar pessoas em situação de rua que precisam de isolamento em imóveis apropriados e fornecer álcool em gel e produtos de higiene para pessoas em situação de vulnerabilidade.

Segundo a perspectiva da bioética social, os parâmetros para a tomada de decisão, tanto no que se refere ao contexto clínico quanto à definição de protocolos, normas e políticas públicas, devem priorizar grupos sociais vulneráveis e excluídos. Nesse sentido, estudos como o de Bezerra e colaboradores ${ }^{48}$, que identificou fatores que interferem no distanciamento social, apontando diferenças nas condições de habitabilidade entre pessoas de maior e menor renda, podem auxiliar o planejamento.

Campos ${ }^{49}$ defende ações de prevenção que não submetam o usuário, mas o incluam, ressaltando que não basta melhorar os dados informados, sendo necessário assegurar a capacidade de compreensão e decisão dos vários setores envolvidos no projeto. O enfrentamento da pandemia de covid-19 requer participação da sociedade na adesão às medidas de 
distanciamento social. Contudo, entende-se que só se consegue genuína adesão e efetiva participação da sociedade em iniciativas do Estado se as pessoas são capazes de entender que a prevenção é de responsabilidade individual ${ }^{49}$.

Pesquisas realizadas após a epidemia de Sars mostram que as pessoas entendem e aceitam a necessidade de medidas restritivas, sendo que muitos as percebem como dever cívico e estão dispostos a sacrificar o direito à livre circulação ${ }^{40}$. Medidas estabelecidas pelo Estado devem ser tomadas de maneira aberta, justa e legítima; a sociedade tem o direito de conhecer as razões da saúde pública para restringir a liberdade ${ }^{34}$.

O Ministério da Saúde da Colúmbia Britânica ${ }^{50}$ divulgou análise ética do cuidado em tempos de covid-19, afirmando que a sociedade tem direito de se proteger de dano real ou ameaça. Assim, o governo tem justificativa para possivelmente intervir nos direitos dos indivíduos para proteger a comunidade contra danos. As autoridades devem impor o menor ônus à autodeterminação pessoal necessário para alcançar o objetivo de conter a pandemia, ou seja, não se pode trocar toda a liberdade por segurança ${ }^{16}$. A proporcionalidade exige que restrições à liberdade individual e medidas para proteger o público da contaminação não excedam o necessário para abordar o nível real de risco ou a demanda da comunidade ${ }^{8}$.

O Centro Conjunto de Bioética da Universidade de Toronto ${ }^{40}$ desenvolveu guia em que se identificam questões éticas importantes a serem abordadas no planejamento contra a pandemia, entre as quais está a necessidade de restringir a liberdade, por medidas como quarentena, pelo interesse da saúde pública. Para tanto, o Estado e o setor de saúde devem garantir que a comunidade esteja ciente dos motivos das medidas restritivas, explicitando os benefícios de cumprir e as consequências de negligenciar as medidas propostas ${ }^{40}$.

Como exposto, as autoridades de saúde pública devem divulgar clara e honestamente as razões para a implementação de medidas de distanciamento social e permitir a participação da comunidade na decisão ${ }^{16}$. Nesse sentido, as autoridades devem garantir a transparência do processo decisório, o que aumenta a confiança do público e a aceitação de medidas propostas para conter a pandemia ${ }^{16,35}$. O envolvimento da sociedade na adoção consciente de medidas de precaução à covid-19 exige mudança de comportamento tanto individual quanto coletivo. Somente com o esforço colaborativo de todos (poder público e cidadãos) será possível diminuir os impactos dessa pandemia no Brasil ${ }^{19}$.

Nesse contexto, ressalta-se que o medo individual e o pânico comunitário associados a doenças infecciosas geralmente levam a decisões apressadas e emotivas sobre políticas de saúde pública, o que pode gerar conflito entre liberdades individuais e autodeterminação ${ }^{34}$. Em vista disso, os profissionais da saúde desempenham papel fundamental para atrair a confiança dos cidadãos, facilitando o entendimento das restrições à autonomia individual acarretadas pelas medidas de distanciamento social. Além disso, também colaboram para a promoção de comportamentos individuais de higiene, os quais ajudam a diminuir a propagação da covid-19.

Os profissionais da saúde são nucleares no planejamento de resposta a situação pandêmica, sendo agentes de decisões sanitárias junto a doentes, familiares e comunidade. Por meio do cuidado integral e humanizado, têm papel vital na luta contra a pandemia, visto que a pluralidade de sua formação e a posição de liderança que ocupam os colocam como protagonistas no combate à transmissão da covid-19.

Reafirma-se ser fundamental promover adesão às medidas de distanciamento social, explicando sua necessidade e seus benefícios, assim como os riscos pessoais e sociais envolvidos em sua inobservância. Além disso, em sociedade caracterizada pelo pluralismo de valores morais, é necessário que as deliberações das autoridades sejam transparentes e abertas ao debate público, gerando decisões claramente articuladas e justificadas para que as pessoas confiem nos serviços e profissionais da linha de frente ${ }^{51}$.

Assim, a atenção cuidadosa aos valores bioéticos em causa na tomada de decisão em saúde coletiva pode promover a cooperação voluntária e a confiança da comunidade ${ }^{34}$. Uma pandemia exige solidariedade entre nações e abordagens colaborativas que deixem de lado valores tradicionais de interesse próprio, voltando o olhar ao coletivo.

\section{Considerações finais}

As questões aqui apresentadas apontam para a necessária indagação: que ações devem ser efetivadas durante uma pandemia? Não se espera, aqui, sugerir ou tentar responder à pergunta, mas instigar 
reflexões acerca da bioética e da saúde coletiva em meio ao contexto atual. A bioética principialista está presente em qualquer decisão que envolva problemas éticos na saúde, ainda que se mostre insuficiente. A bioética social, por sua vez, parece ser complementar à ética em saúde coletiva, por basear seu discurso em valores comunitários e sociais.

O conflito de valores entre o benefício coletivo (por meio da adoção de medidas de distanciamento social) e a restrição das liberdades individuais abre espaço para a reflexão bioética e cria ambiente propício para discutir e aperfeiçoar práticas de cuidado. Riscos, erros e acertos são inerentes ao processo decisório em tempos de pandemia. Não existe resposta absolutamente correta para o problema, sendo a abordagem mais viável encontrar solução que seja compreendida e aceita pela população.

Apresentam-se por fim algumas considerações bioéticas que podem ser contempladas por todos os atores envolvidos no processo de produção de saúde em tempos de pandemia:

- Usuários precisam ser capazes de avaliar em que medida suas escolhas podem prejudicar o outro ou a sociedade, pois a liberdade pressupõe cidadãos responsáveis e conscientes dos resultados e das consequências de suas opções e ações, tanto em âmbito individual quanto coletivo. Uma população bem informada durante a pandemia é vital para o sucesso de qualquer ação de enfrentamento, que em última instância depende da mobilização e do protagonismo da sociedade civil.

- Profissionais da saúde precisam considerar os fatos científicos para a tomada de decisão, assumindo o propósito de cuidar bem de todos. O cuidado realizado pelos profissionais da atenção primária à saúde deve orientar casos suspeitos quanto a distanciamento social e reconhecimento dos sinais de alerta, monitorando a evolução clínica de tais casos. É importante não fazer leituras bioéticas reducionistas que induzam a deliberação a partir de um único princípio.

- O Estado tem obrigação moral e constitucional de propor políticas e coordenar ações de emergência adequadas para controlar, superar e reduzir os impactos causados pela covid-19. Da mesma forma, os gestores precisam implementar medidas sanitárias e epidemiológicas e propor estratégias de proteção social que impactem positivamente o sistema de saúde, pois suas ações podem tanto salvar vidas quanto causar mais mortes. Também urge fortalecer a cooperação entre municípios, estados e União.

Considera-se, finalmente, que medidas de distanciamento social são viáveis e têm sucesso quando usuários, profissionais e gestores estão mobilizados em regime de coesão firme e solidária.

\section{Referências}

1. Chan JFW, Yuan S, Kok KH, To KKW, Chu H, Yang J et al. A familial cluster of pneumonia associated with the 2019 novel coronavirus indicating person-to-person transmission: a study of a family cluster. Lancet [Internet]. 2020 [acesso 23 mar 2020];395(10223):514-23. DOI: 10.1016/S0140-6736(20)30154-9

2. Li H, Liu L, Zhang D, Xu J, Dai H, Tang N et al. Sars-CoV-2 and viral sepsis: observations and hypotheses. Lancet [Internet]. 2020 [acesso 10 maio 2020];395(10235):1517-20. DOI: 10.1016/S0140-6736(20)30920-X

3. Covid-19 in Brazil: "so what?". Lancet [Internet]. 2020 [acesso 10 maio 2020];395(10235):1461. DOI: 10.1016/S0140-6736(20)31095-3

4. Brasil. Ministério da Saúde. Secretaria de Vigilância em Saúde. Centro de Operações de Emergência em Saúde Pública. COE-Covid19. Bol Epidemiol Espec [Internet]. 2020 [acesso 10 maio 2020];14. Disponível: https://bit.ly/3iXo1WF

5. Prem K, Liu Y, Russell TW, Kucharski AJ, Eggo RM, Davies N et al. The effect of control strategies to reduce social mixing on outcomes of the covid-19 epidemic in Wuhan, China: a modelling study. Lancet Public Health [Internet]. 2020 [acesso 10 maio 2020];5(5):E261-70. DOI: 10.1016/S2468-2667(20)30073-6

6. Folha informativa covid-19: Escritório da Opas e da OMS no Brasil. Organização Pan-Americana da Saúde [Internet]. 2020 [acesso 28 set 2020]. Disponível: https://bit.ly/2KZseMQ 
7. Kraemer MUG, Yang CH, Gutierrez B, Wu CH, Klein B, David M et al. The effect of human mobility and control measures on the covid-19 epidemic in China. Science [Internet]. 2020 [acesso 10 maio 2020];368(6490):493-7. DOI: 10.1126/science.abb4218

8. Thompson AK, Faith K, Gibson JL, Upshur REG. Pandemic influenza preparedness: an ethical framework to guide decision-making. BMC Med Ethics [Internet]. 2006 [acesso 10 maio 2020];7:12. DOI: 10.1186/ 1472-6939-7-12

9. Zoboli ELCP. Bioética: gênese, conceituação e enfoques. In: Oguisso T, Zoboli ELCP, organizadores. Ética e bioética: desafios para a enfermagem e a saúde. Barueri: Manole; 2006. p. 111-35.

10. Junges JR, Zoboli ELCP. Bioética e saúde coletiva: convergências epistemológicas. Ciênc Saúde Coletiva [Internet]. 2012 [acesso 10 maio 2020];17(4):1049-60. DOI: 10.1590/S1413-81232012000400026

11. Kotaki E. Morador de rua com coronavírus foge de isolamento em albergue e é preso em MT. G1 [Internet]. 21 maio 2020 [acesso 27 jan 2021]. Disponível: https://glo.bo/3iYwGrP

12. Santiago A. Jovem com covid-19 sai de quarentena, vai a festa e futebol e é preso no RS. UOL [Internet]. 22 mar 2020 [acesso 27 jan 2021]. Disponível: https://bit.ly/39wTN9Y

13. MP vai investigar conduta de homem com covid-19 que desrespeitou isolamento e foi a restaurante em SC. G1 [Internet]. 15 jun 2020 [acesso 27 jan 2021]. Disponível: https://glo.bo/2NJpeVT

14. Beauchamp T, Childress J. Principles of biomedical ethics. $8^{\text {a }}$ ed. New York: Oxford University Press; 2019.

15. Sanches MA, Cunha TR, Siqueira SS, Siqueira JE. Perspectivas bioéticas sobre tomada de decisão em tempos de pandemia. Rev. bioét. (Impr.) [Internet]. 2020 [acesso 28 set 2020];28(3):410-7. DOI: 10.1590/ 1983-80422020283401

16. Institute of Medicine. Ethical and legal considerations in mitigating pandemic disease: workshop summary [Internet]. Washington: The National Academies Press; 2007 [acesso 10 maio 2020]. DOI: 10.17226/11917

17. Wilder-Smith A, Freedman DO. Isolation, quarantine, social distancing and community containment: pivotal role for old-style public health measures in the novel coronavirus (2019-nCoV) outbreak. J Travel Med [Internet]. 2020 [acesso 10 maio 2020];27(2):taaa020. DOI: 10.1093/jtm/taaa020

18. Brasil. Ministério da Saúde. Secretaria de Vigilância em Saúde. Centro de Operações de Emergência em Saúde Pública. Especial: doença pelo coronavírus 2019. Bol Epidemiol [Internet]. 2020 [acesso 29 jan 2021];7. Disponível: https://bit.ly/2Mh5usf

19. Oliveira AC, Lucas TC, Iquiapaza RA. O que a pandemia da covid-19 tem nos ensinado sobre adoção de medidas de precaução? Texto Contexto Enferm [Internet]. 2020 [acesso 11 maio 2020];29:e20200106. DOI: 10.1590/1980-265X-TCE-2020-0106

20. Brasil. Ministério da Saúde. Painel coronavírus [Internet]. 2020 [acesso 10 maio 2020]. Disponível: https://bit.ly/3t9JgZN

21. Brama GMR, Grisólia CK. Bio(ética) ambiental: estratégia para enfrentar a vulnerabilidade planetária. Rev. bioét. (Impr.) [Internet]. 2012 [acesso 11 maio 2020];20(1):41-8. Disponível: https://bit.ly/3r4jBQx

22. Mill JS. A liberdade/Utilitarismo. São Paulo: Martins Fontes; 2000.

23. Ugarte ON, Acioly MA. O princípio da autonomia no Brasil: discutir é preciso. Rev Col Bras Cir [Internet]. 2014 [acesso 11 maio 2020];41(5):274-7. DOI: 10.1590/0100-69912014005013

24. Zoboli ELCP, Kipper DJ. Bioética clínica. São Paulo: Gaia; 2008.

25. Wehmeyer ML. A functional model of self-determination: describing development and implementing instruction. Focus Autism Other Dev Disabl [Internet]. 1999 [acesso 29 jan 2021];14(1):53-62. DOI: $10.1177 / 108835769901400107$

26. Brasil. Constituição da República Federativa do Brasil de 1988. Diário Oficial da União [Internet]. Brasília, 5 out 1988 [acesso $1^{\circ}$ out 2020]. Disponível: https://bit.ly/3cqHn58

27. Bacellar Filho RF. Direito administrativo. $4^{a}$ ed. São Paulo: Saraiva; 2008.

28. Lessa SC, Dórea JG. Bioética e vacinação infantil em massa. Rev. bioét. (Impr.) [Internet]. 2013 [acesso $1^{\circ}$ out 2020];21(2):226-36. DOI: 10.1590/S1983-80422013000200005 
29. Brasil. Lei $\mathrm{n}^{\circ}$ 13.979, de 6 de fevereiro de 2020. Dispõe sobre as medidas para enfrentamento da emergência de saúde pública de importância internacional decorrente do coronavírus responsável pelo surto de 2019. Diário Oficial da União [Internet]. Brasília, p. 1, 7 fev 2020 [acesso 29 jan 2021]. Disponível: https://bit.ly/36oqggp

30. Bonita R, Beaglehole R, Kjellstrom T. Epidemiologia básica. $2^{\text {a }}$ ed. São Paulo: Santos; 2010.

31. Silva LJ. Da vacina à aspirina: considerações acerca das ações coletivas em saúde pública. Saúde Soc [Internet]. 1996 [acesso $1^{\circ}$ out 2020];5(2):3-16. DOI: 10.1590/S0104-12901996000200002

32. Medeiros MOSF, Meira MV, Fraga FMR, Nascimento Sobrinho CL, Rosa DOS, Silva RS. Conflitos bioéticos nos cuidados de fim de vida. Rev. bioét. (Impr.) [Internet]. 2020 [acesso 11 maio 2020];28(1):128-34. DOI: 10.1590/1983-80422020281375

33. Public Health Leadership Society. Principles of the ethical practice of public health: version 2.2 [Internet]. Washington: Public Health Leadership Society; 2002 [acesso 11 maio 2020]. Disponível: https://bit.ly/39tyMg1

34. Cetron M, Landwirth J. Public health and ethical considerations in planning for quarantine. Yale J Biol Med [Internet]. 2005 [acesso 11 maio 2020];78(5):329-34. Disponível: https://bit.ly/2YpYJHO

35. Conselho Nacional de Ética para as Ciências da Vida. Situação de emergência de saúde pública pela pandemia covid-19: aspetos éticos relevantes: posição do Conselho Nacional de Ética para as Ciências da Vida [Internet]. Lisboa: Conselho Nacional de Ética para as Ciências da Vida; 2020 [acesso 11 maio 2020]. Disponível: https://bit.ly/3t7Z7Z4

36. Nora CRD, Deodato S, Vieira MMS, Zoboli ELCP. Elementos e estratégias para a tomada de decisão ética em enfermagem. Texto Contexto Enferm [Internet]. 2016 [acesso 11 maio 2020];25(2):e4500014. DOI: 10.1590/0104-07072016004500014

37. Zoboli ELCP, Fortes APC. Bioética e atenção básica: um perfil dos problemas éticos vividos por enfermeiros e médicos do Programa Saúde da Família, São Paulo, Brasil. Cad Saúde Pública [Internet]. 2004 [acesso 11 maio 2020];20(6):1690-9. DOI: 10.1590/S0102-311X2004000600028

38. Junges JR. Direito à saúde, biopoder e bioética. Interface Comun Saúde Educ [Internet]. 2009 [acesso 11 maio 2020];13(29):285-95. DOI: 10.1590/S1414-32832009000200004

39. Isailă OM, Hostiuc S. O dever de tratar no contexto da pandemia de covid-19. Rev. bioét. (Impr.) [Internet]. 2020 [acesso 30 set 2020];28(3):426-31. DOI: 10.1590/1983-80422020283403

40. University of Toronto. Joint Centre for Bioethics. Pandemic Influenza Working Group. Stand on guard for thee: ethical considerations in preparedness planning for pandemic influenza [Internet]. Toronto: University of Toronto; 2005 [acesso 11 maio 2020]. Disponível: https://bit.ly/36lzM3R

41. Wanssa MCD. Autonomia versus beneficência. Rev. bioét. (Impr.) [Internet]. 2011 [acesso 11 maio 2020];19(1):105-17. Disponível: https://bit.ly/3otDsXx

42. Schramm FR. Bioética da proteção em saúde pública. In: Fortes PAC, Zoboli ELCP, organizadores. Bioética e saúde pública. São Paulo: Loyola; 2003. p. 71-84.

43. Vasconcelos MF, Costa SFG, Lopes MEL, Abrão FMS, Batista PSS, Oliveira RC. Cuidados paliativos em pacientes com HIV/aids: princípios da bioética adotados por enfermeiros. Ciênc Saúde Coletiva [Internet]. 2013 [acesso 11 maio 2020];18(9):2559-66. DOI: 10.1590/S1413-81232013000900010

44. Schramm FR. Bioética de proteção: ferramenta válida para enfrentar problemas morais na era da globalização. Rev. Bioética [Internet]. 2008 [acesso 14 maio 2020];16(1):11-23. Disponível: https://bit.ly/2UDcRKR

45. Organização das Nações Unidas. Declaração universal dos direitos humanos [Internet]. Brasília: Unesco; 1998 [acesso 24 fev 2021]. Disponível: https://bit.ly/2GDR1E3

46. Schramm FR, Kottow M. Principios bioéticos en salud pública: limitaciones y propuestas. Cad Saúde Pública [Internet]. 2001 [acesso 7 maio 2020];17(4):949-56. DOI: 10.1590/S0102-311X2001000400029

47. Frente pela Vida. Plano nacional de enfrentamento à pandemia da covid-19 [Internet]. Rio de Janeiro: Associação Brasileira de Saúde Coletiva; 2020 [acesso 5 out 2020]. Disponível: https://bit.ly/3c6xUht 
48. Bezerra ACV, Silva CEM, Soares FRG, Silva JAM. Fatores associados ao comportamento da população durante o isolamento social na pandemia de covid-19. Ciênc Saúde Coletiva [Internet]. 2020 [acesso 5 out 2020];25(supl 1):2411-21. DOI: 10.1590/1413-81232020256.1.10792020

49. Campos GWS. Saúde paideia. São Paulo: Hucitec; 2003.

50. British Columbia. Ministry of Health. Provincial Covid-19 Task Force. Covid-19 ethics analysis: what is the ethical duty of health care workers to provide care during covid-19 pandemic? [Internet]. Vancouver: British Columbia Ministry of Health; 2020 [acesso 5 out 2020]. Disponivel: https://bit.ly/3orCWJT

51. Fortes PAC, Pereira PCA. Priorização de pacientes em emergências médicas: uma análise ética. Rev Assoc Méd Bras [Internet]. 2012 [acesso 11 maio 2020];58(3):335-40. DOI: 10.1590/ S0104-42302012000300014 